Ki net i c Resol ut i on of Pri mary Ami nes vi a Enant i osel ect i ve $\mathrm{N}$ Acyl at i on wi th Acyl Chl or i des i $n$ the Presence of Supramol ecul ar Cycl odext ri n Nanocapsul es

\begin{tabular}{|l|l|}
\hline 著者 & $\begin{array}{l}\text { Asahar a Har uyasu, K da Toshi yuki , I wanmt o } \\
\text { Takuya, Hi noue Tombaki, Akashi M t sur u }\end{array}$ \\
\hline $\begin{array}{l}\text { j our nal or } \\
\text { publ i cat i on t i t l e }\end{array}$ & Tet rahedr on \\
\hline vol une & 70 \\
\hline number & 2 \\
\hline page r ange & $197-203$ \\
\hline year & 2014 \\
\hline URL & ht t p: //hdl . handl e. net /10173/1331 \\
\hline
\end{tabular}




\title{
Kinetic Resolution of Primary Amines via Enantioselective $N$-Acylation with Acyl Chlorides in the Presence of Supramolecular Cyclodextrin Nanocapsules
}

\author{
Haruyasu Asahara ${ }^{\text {a }}$, Toshiyuki Kida a , Takuya Iwamoto ${ }^{\text {a }}$, Tomoaki Hinoue a, and Mitsuru Akashi ${ }^{\text {a,* }}$ \\ ${ }^{a}$ Department of Applied Chemistry, Graduate School of Engineering, Osaka University, 2-1 Yamada-oka, Suita, Osaka 565-0871, Japan
}

\section{ARTICLE INFO}

Article history:

Received

Received in revised form

Accepted

Available online

Keywords:

Cyclodextrin

Kinetic Resolution

Supramolecular Nanocapsule

Acyl Chloride

Inclusion Complex

\section{ABSTRACT}

The non-enzymatic kinetic resolution of primary amines via enantioselective $N$-acylation with acyl chlorides was accomplished for the first time by using the selective sequestration of one enantiomer within a supramolecular cyclodextrin (CD) nanocapsule in nonpolar solvents. In addition, the first example of a crystalline structure for an inclusion complex between an acyl chloride and a CD derivative is reported.

2009 Elsevier Ltd. All rights reserved.

\section{Introduction}

Enantiomerically pure amines and amides are ubiquitous substructures in biologically active compounds, pharmaceuticals, and chiral catalysts. ${ }^{1}$ The kinetic resolution (KR) of a racemic amine is one of the most useful methods to access optically pure amines. Since the first report by Fu's group, ${ }^{2}$ a great deal of attention has been paid to non-enzymatic acylation processes for the KR of racemic amines. ${ }^{2,3}$ In most cases, less reactive acylation reagents and considerably lower temperatures were needed for the KR of amines due to their high reactivity.

Supramolecular nanocapsules formed by the self-assembly of molecular building blocks have attracted considerable attention due to their ability to act as reaction vessels and confinement containers. ${ }^{4}$ Recently, Gibb et al. reported the KR of constitutional isomers of long-chain esters utilizing a selfassembled supramolecular nanocapsule as a means for selective protection. $^{5}$ In this system, one isomer was selectively encapsulated into the supramolecular nanocapsule cavity, and thus its hydrolysis was remarkably inhibited. More recently, we reported the high chiral recognition and KR of primary amines utilizing a supramolecular chiral nanocapsule assembled by 6-Otriisopropylsilylated $\beta$-cyclodextrin (TIPS- $\beta$-CD) in nonpolar solvents. $^{6}$ In particular, the KR of racemic 1-(1naphthyl)ethylamine (1-NEA) was achieved via enantioselective $\mathrm{N}$-acylation with benzoic anhydride in the presence of this supramolecular chiral nanocapsule with an enantiomeric excess of up to $91 \%$. This result implies that the supramolecular cyclodextrin nanocapsule can potentially function as a powerful tool for the KR of highly reactive chemical species including primary amines. The application of this supramolecular chiral nanocapsule to the $\mathrm{KR}$ of racemic amines with commonly used acylation reagents, such as acyl chlorides, will greatly increase its synthetic utility. In general, it has been considered that the reactivity of acyl chlorides is too high to use as acylation reagents in $\mathrm{KR},{ }^{7}$ although acyl chlorides are the most useful acylation reagents from the viewpoints of accessibility and reactivity. Herein, we report the first example of the KR of primary amines through enantioselective $N$-acylation with acyl chlorides utilizing the selective sequestration of one enantiomer within the supramolecular CD nanocapsule.

\section{Results and Discussion}

\subsection{The formation of inclusion complexes between 6-O-modified CDs and primary amines}

Based on our recent finding, ${ }^{6} \quad(R)$ - and $(S)-1-(1-$ naphthyl)ethylamine $[(R)-$ and $(S)-1], \quad(R)-$ and $(S)-1-(2-$ naphthyl)ethylamine $[(R)-$ and $(S)-2]$, and $(R)$ - and $(S)-1-(1-$ phenyl)ethylamine $[(R)$ - and $(S)-3]$ (Figure 1 ) were chosen as primary amine substrates. 6-O-tert-butyldimethylsilylated $\beta$ cyclodextrin (TBDMS- $\beta-C D$ ) and TIPS- $\beta$-CD (Figure 1) were used as components of supramolecular $\mathrm{CD}$ capsules. Table 1 summarizes the association constants $(K)$ between these 6-Osilylated $\beta$-CDs and the chiral amines in benzene- $d_{6}$ or cyclohexane- $d_{12}$, and the chiral selectivity $\left(K_{S} / K_{R}\right)$. In this study, we newly determined the association constants between TBDMS- $\beta-C D$ and $(R)$ - or $(S)-\mathbf{1}$ and between TIPS- $\beta-C D$ and $(R)$ - or $(S)-3$ by a NMR titration method. Shifts of the $\mathrm{H}_{3}$ and $\mathrm{H}_{5}$ proton signals of TBDMS- $\beta$-CD upon the addition of $(R)$ - or $(S)$ 1 were observed in cyclohexane- $d_{12}$ (Figure S1, Supporting Information), suggesting the formation of a TBDMS- $\beta-C D-(R)-$ 


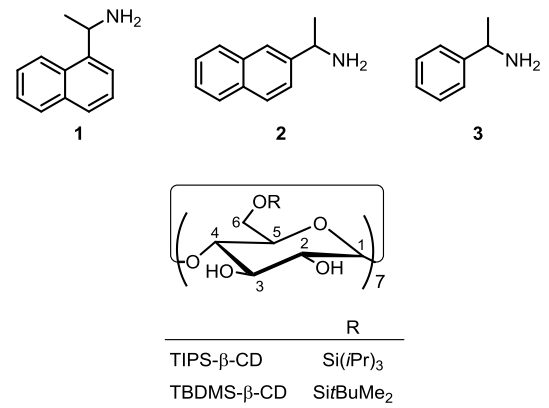

Figure 1. Primary amines 1-3 and 6- $O$-silylated CDs used in this study.

or $(S)$-1 complex. Job plots using a NMR method showed a maximum at a [TBDMS- $\beta-\mathrm{CD}] /[(R)-$ or $(S)-\mathbf{1}]$ molar ratio of $2: 1$ (Figure S5, Supporting Information), indicating that TBDMS- $\beta$ CD formed a 2:1 complex with $(R)$ - or $(S)$-1. This result demonstrates that a supramolecular dimer capsule of TBDMS- $\beta$ $\mathrm{CD}$ incorporates these chiral guests inside the cavity. The chiral recognition ability of the supramolecular TBDMS- $\beta-C D$ nanocapsule towards 1 was lower than that of the supramolecular nanocapsule derived from TIPS- $\beta$-CD (Table 1 , entries 2 and 4 ), showing that a difference in the substituents on the $\mathrm{Si}$ atom between TBDMS- $\beta-C D$ and TIPS- $\beta-C D$ has large effect on the chiral recognition in nonpolar solvents. On the other hand, when $(R)$ - or $(S)$-3 bearing a phenyl group was used as a guest, Job plots showed the formation of a 1:1 complex with TIPS- $\beta-C D$ (Figure S6, Supporting Information), in contrast to the complexes between TIPS- $\beta-C D$ and other chiral guests bearing a naphthyl group with 2:1 molar ratios. Even when the supramolecular TIPS- $\beta$-CD nanocapsule was used, little chiral selectivity for $\mathbf{3}$ $\left(K_{\mathrm{S}} / K_{\mathrm{R}}=1.0\right)$ was observed. This result indicates that the presence of the supramolecular dimer capsule plays a crucial role for the high chiral recognition.

\subsection{Enantioselective $N$-acylation of primary amines in the presence of supramolecular 6-O-modified CDs nanocapsules}

On the basis of the results mentioned in Section 2.1, the enantioselective $N$-acylation of racemic amines 1-3 with benzoyl chloride $\mathbf{4 a}$ in the presence of the supramolecular TIPS- $\beta-C D$ nanocapsule was examined. Similar to our recent study using acid anhydride as an acylation reagent, ${ }^{6}$ cyclohexane was chosen as the solvent, in which the supramolecular TIPS- $\beta$-CD nanocapsule showed high chiral recognition towards 1 (Table 1, entry 1). A mixture of primary amines 1-3, TIPS- $\beta$-CD (5.0 equiv), and triethylamine (1.0 equiv) in cyclohexane was stirred for $1 \mathrm{~h}$ to reach complexation equilibrium. Then benzoyl chloride 4a ( 0.5 equiv) was added at $10{ }^{\circ} \mathrm{C}$, and the mixture was stirred at $10{ }^{\circ} \mathrm{C}$ for $6 \mathrm{~h}$. Table 2 shows the conversion of $\mathbf{1 - 3}$, the enantiomeric excess (ee, \%) of the resulting $N$-benzoyl- $(R)$ amines, and the s-factor $(s) .{ }^{8}$ The enantioselective $N$-acylation of 1 with $4 \mathbf{a}$ exceeded $77 \%$ ee (Table 2, entry 1 ). As expected from the lower chiral recognition capability of the supramolecular TIPS- $\beta$-CD nanocapsule towards $\mathbf{2}$ and $\mathbf{3}$ as compared to $\mathbf{1}$ (Table 1), the reactions of these amines with $\mathbf{4 a}$ proceeded with lower enantioselectivity (Table 2, entries 2 and 3 ). These results confirm that the origin of the enantioselectivity in this reaction system should be the selective sequestration of one isomer of the amines within the supramolecular CD nanocapsule. The ${ }^{1} \mathrm{H}$ NMR spectra of the products showed that no reaction occurred between the free $\mathrm{OH}$ group of TIPS- $\beta-\mathrm{CD}$ and $\mathbf{4 a}$ under these conditions. ${ }^{9}$

A larger scale reaction of racemic amine $1(0.1 \mathrm{mmol})$ with 4 a $(0.05 \mathrm{mmol})$ proceeded with the almost same conversion and
Table 2. Enantioselective $N$-acylation of primay amines 1, 2, and $\mathbf{3}$ with benzoyl chloride $\mathbf{4 a}$ in the presence of TIPS- $\beta$-CD in cyclohexane at $10^{\circ} \mathrm{C}^{\mathrm{a}}$

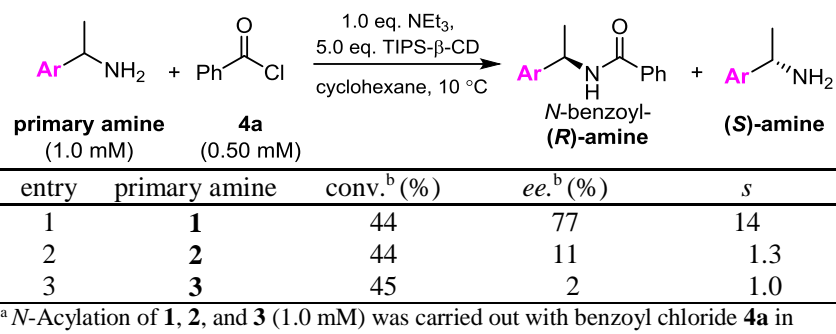

nonpolar solvents $(0.6 \mathrm{~mL})$ at $10{ }^{\circ} \mathrm{C}$ for $12 \mathrm{~h}$ in the presence of TIPS- $\beta$-CD (5.0 equiv) and triethylamine (1.0 equiv).

${ }^{\mathrm{b}}$ Conversion of $\mathbf{1}, \mathbf{2}$, and $\mathbf{3}$ and enantiomeric excess of $N$-benzoyl-( $R$-) amines were determined by HPLC.

selectivity (conv. $=46 \%, e e=76 \%, s=14$ ) as those of the abovementioned micromole scale reaction (Table 2 , entry 1 ). This result indicates that the enantioselective $N$-acylation of the primary amines with acyl chlorides in the presence of the supramolecular TIPS- $\beta$-CD nanocapsule is little affected by the reaction scale.

Using $\mathbf{1}$ and $\mathbf{4 a}$ as an amine substrate and an acylation reagent, respectively, we examined the effect of the reaction conditions, such as the amount of $\mathrm{CD}$, the solvent type, temperature, and the CD type, on the enantioselective $N$-acylation (Table 3). Decreasing the molar ratio of $\mathbf{4 a}$ to $\mathbf{1}$ in the presence of 5.0 equiv of TIPS- $\beta$-CD increased the enantioselectivity (Table 3, entries 2-4). In particular, the $N$-acylation of 1 with 0.1 equiv of $\mathbf{4 a}$ in the presence of 5.0 equiv of TIPS- $\beta-C D$ proceeded with the highest enantioselectivity and s-factor $(90 \% e e, s=20)$. A decrease in the amount of TIPS- $\beta$-CD from 5.0 to 1.0 equiv largely decreased the enantioselectivity (Table 3, entries 4 and 5), suggesting that the presence of the dimer capsule of TIPS- $\beta$-CD is essential to the high enantioselectivity. When benzene was used as a solvent, the ee decreased to $54 \%$ (Table 3, entry 6). This decrease can be explained by a decrease in the chiral recognition capability of the supramolecular TIPS- $\beta-C D$ nanocapsule towards $\mathbf{1}$ with the change in solvent from cyclohexane to benzene (Table 1, entries 1 and 3). An increase in the reaction temperature to $25{ }^{\circ} \mathrm{C}$ lowered the enantioselectivity (Table 3, entry 8), possibly due to a decrease in the chiral selectivity of the supramolecular nanocapsule towards 1 (Table 1, entry 2). When TBDMS- $\beta$-CD was used as the component of the

Table 3. Enantioselective $N$-acylation of $\mathbf{1}$ with benzoyl chloride $\mathbf{4 a}$ in the presence and absence of 6- $O$-silylated- $\beta-\mathrm{CD}$ in nonpolar solvents ${ }^{\mathrm{a}}$

\begin{tabular}{|c|c|c|c|c|c|c|}
\hline Entry & CDs & $\mathbf{4 a}(\mathrm{mM})$ & solvent & conv. (\%) & $e e^{\mathrm{b}}(\%)$ & $s$ \\
\hline 1 & - & 0.50 & $c-\mathrm{C}_{6} \mathrm{H}_{12}$ & 47 & - & - \\
\hline 2 & TIPS- $\beta-C D$ & 0.10 & $c-\mathrm{C}_{6} \mathrm{H}_{12}$ & 7 & 90 & 20 \\
\hline 3 & TIPS- $\beta-C D$ & 0.40 & $c-\mathrm{C}_{6} \mathrm{H}_{12}$ & 33 & 84 & 17 \\
\hline 4 & TIPS- $\beta-C D$ & 0.50 & $c-\mathrm{C}_{6} \mathrm{H}_{12}$ & 44 & 77 & 14 \\
\hline 5 & TIPS- $\beta-C D^{c}$ & 0.50 & $c-\mathrm{C}_{6} \mathrm{H}_{12}$ & 47 & 45 & 4 \\
\hline 6 & TIPS- $\beta-C D$ & 0.50 & $\mathrm{C}_{6} \mathrm{H}_{6}$ & 48 & 54 & 6 \\
\hline 7 & TBDMS- $\beta-C D$ & 0.50 & $c-\mathrm{C}_{6} \mathrm{H}_{12}$ & 48 & 21 & 2 \\
\hline 8 & TIPS- $\beta-C D^{d}$ & 0.50 & $c-\mathrm{C}_{6} \mathrm{H}_{12}$ & 41 & 66 & 8 \\
\hline 9 & TIPS- $\beta-C D^{\mathrm{e}}$ & 0.50 & $c-\mathrm{C}_{6} \mathrm{H}_{12}$ & 40 & 71 & 9 \\
\hline
\end{tabular}

${ }^{a} N$-Acylation of $1(1.0 \mathrm{mM})$ was carried out with benzoyl chloride $\mathbf{4 a}$ in nonpolar solvents $(0.6 \mathrm{~mL})$ at $10^{\circ} \mathrm{C}$ for $6 \mathrm{~h}$ in the presence of CDs (5.0 equiv to 1$)$ and triethylamine (1.0 equiv).

${ }^{\mathrm{b}}$ Conversion of 1 and enantiomeric excess of $(R)$-5a were determined by HPLC

$c 1.0$ equiv of TIPS- $\beta-C D$ was used.

${ }^{d}$ In the absence of $\mathrm{NEt}_{3}$. 
supramolecular nanocapsule instead of TIPS- $\beta-C D$, much lower enantioselectivity was obtained (Table 3 , entry 7 ). These results clearly show that the key step in the enantioselective $N$-acylation is the selective inclusion of $(S)$-1 over $(R)-\mathbf{1}$ within the supramolecular capsule cavity. Interestingly, there was no significant difference in the enantioselectivity and s-factor $(s)$ for the enantioselective $N$-acylation of $\mathbf{1}$ in the presence of TIPS- $\beta$ $\mathrm{CD}$ between benzoyl chloride $\mathbf{4 a}$ and benzoic anhydride (conv. = $7 \%, e e=91 \%, s=23$; conv. $=49 \%, e e=75, s=15),{ }^{6}$ suggesting that the supramolecular CD nanocapsule can be applied to the KR of primary amines with not only acid anhydride, but also with more reactive acyl chlorides. ${ }^{7}$ To the best of our knowledge, this is the first report of the enantioselective $\mathrm{N}$-acylation of a primary amine with acyl chloride as an acylation reagent.

We also examined the enantioselective $N$-acylation of $\mathbf{1}$ with a variety of acyl chlorides $\mathbf{4 b - j}$ in the presence of the supramolecular TIPS- $\beta$-CD nanocapsule (Table 4). The $\mathrm{N}$ acylation of 1 was carried out with acyl chloride ( 0.5 equiv) in cyclohexane at $10{ }^{\circ} \mathrm{C}$ for $5 \mathrm{~h}$ in the presence of TIPS- $\beta$-CD $(5.0$ equiv) and triethylamine (1.0 equiv). Most of the acyl chlorides examined here afforded the corresponding amide with moderate to good enantioselectivities. In particular, acyl chlorides bearing a phenyl (Table 4, entry 1), hexyl (Table 4, entry 5), cyclohexyl (Table 4, entry 6), and 1-adamantyl group (Table 4, entry 7) gave $\mathrm{N}$-acylation products with higher enantioselectivity. On the other hand, when acetyl chloride, which bears a less bulky methyl group, was used, the enantioselectivity decreased (Table 4, entry 2 ). In the reaction of 1 with 1 -naphthoyl chloride $4 \mathbf{i}$, the conversion was low but with good enantioselectivity. In sharp contrast to these cases, the reaction of 1 with 2,4,6trimethylbenzoyl chloride $\mathbf{4 j}$ did not proceed under these conditions (Table 4, entry 10), possibly due to the large steric bulkiness of $\mathbf{4 j}$. These results clearly show that the use of acyl chloride with an appropriately bulky substituent is required for the $N$-acylation of $\mathbf{1}$ with high enantioselectivity.

\subsection{The formation of inclusion complexes between TIPS- $\beta$-CDs and acyl chlorides}

Interestingly, it was found that TIPS- $\beta$-CD formed inclusion complexes with adamantoyl chloride 4g, 2,4-dichlorobenzoyl chloride $\mathbf{4 h}$, and 1-naphthoyl chloride $\mathbf{4} \mathbf{i}$ in cyclohexane- $d_{12}$ by NMR studies (Figures 2 and Figures S3 and S4, Supporting Information). Job plots using the NMR method (Figures S7-9, Supporting Information) showed a maximum at a [TIPS- $\beta$ $\mathrm{CD}] /[\mathbf{4 g}-\mathbf{i}]$ molar ratio of $2: 1$ in cyclohexane- $d_{12}$, clearly indicating that TIPS- $\beta$-CD formed a 2:1 complex with $\mathbf{4 g - i}$. The association constants $(K)$ between TIPS- $\beta$-CD and $\mathbf{4 g - i}$, which were estimated from the ${ }^{1} \mathrm{H}$ NMR spectral changes upon the addition of the acyl chlorides, were shown in Table 4. TIPS- $\beta$ -

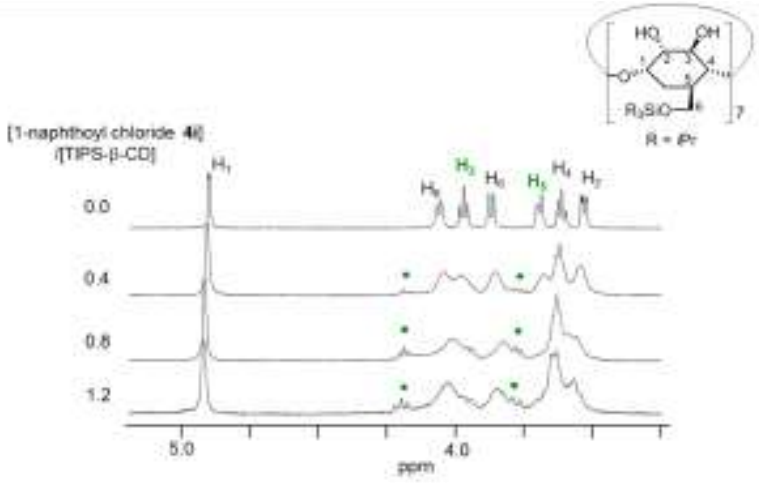

Figure 2. ${ }^{1} \mathrm{H}$ NMR spectral changes observed for TIPS- $\beta$-CD $\left(1.0 \times 10^{-3} \mathrm{M}\right)$ upon the addition of 1-naphthoyl chloride $4 \mathbf{i}$ in cyclohexane- $d_{12}$ at $25^{\circ} \mathrm{C}$. Green circles denote newly-appeared signals.

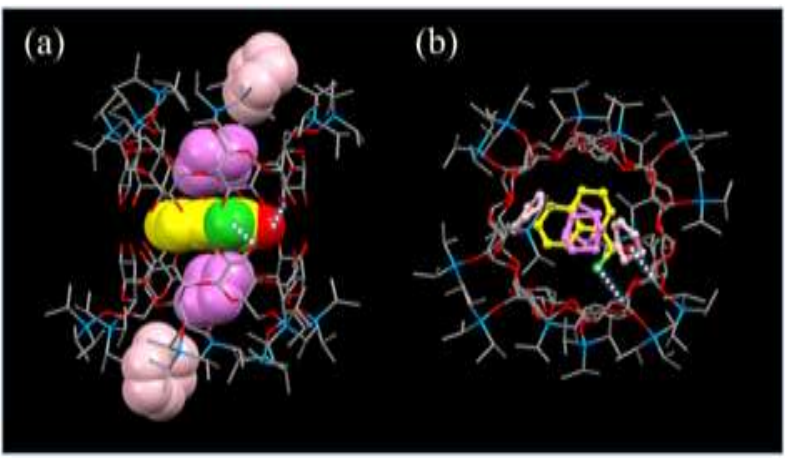

Figure 3. Crystal structure of the TIPS- $\beta-C D-\mathbf{4 i}$ inclusion complex. (a) Side view: TIPS- $\beta$-CD is shown with a cylinder representation, whereas $\mathbf{4 i}$ and cyclohexane are shown with space-filling representations. The hydrogen atoms in all compounds are omitted for clarity. (b) Top view: TIPS- $\beta$-CD is shown with a cylinder representation, whereas $\mathbf{4 i}$ and cyclohexane are shown with ball-and-stick representations. Color labels: gray, carbon in TIPS- $\beta-C D$; cyan, silicon; red, oxygen; green, chloride in $4 \mathbf{i}$; yellow, naphthalene ring and carbon in $\mathbf{4 i}$; violet, cyclohexane molecules interacting with $\mathbf{4 i}$; pink, cyclohexane molecules incorporated near the C-6 position of TIPS- $\beta-C D$; white dotted line, hydrogen bonds between a carbonyl oxygen of $4 \mathbf{i}$ and the 3-OH group of TIPS- $\beta-C D$ and between the chloride of $\mathbf{4 i}$ and the $3-\mathrm{OH}$ group of TIPS- $\beta-\mathrm{CD}$.

Assuming that the cavity shape of the supramolecular TIPS- $\beta$-CD nanocapsule is an ellipsoid, the cavity volume is estimated to be $0.58 \mathrm{~nm}^{3}$ (Figure S27).

CD showed higher inclusion capability towards $4 \mathbf{i}$ than towards $\mathbf{4 g}$ and $\mathbf{4 h}$ in cyclohexane- $d_{12}$ (Table 4 , entries 7-9), possibly due to a better spatial fit of $\mathbf{4 i}$ within the cavity of TIPS- $\beta$-CD dimer. These results show that the supramolecular TIPS- $\beta-C D$ nanocapsule incorporates $\mathbf{4 i}$ within the cavity more stably, resulting in the large inhibition of the $N$-acylation of $\mathbf{1}$.

Crystals of the inclusion complex between the TIPS- $\beta-C D$ supramolecular nanocapsule and $\mathbf{4 i}$ were obtained from the cyclohexane solution. The X-ray crystalline structure showed that the $4 \mathbf{i}$ molecule was included within the cavity of the TIPS- $\beta-C D$ dimer in a similar fashion to a TIPS- $\beta-C D-(S)-1-(1-$ naphthyl)ethylamine ${ }^{6}$ or TIPS- $\beta-C D-$ pyrene $^{10}$ complex previously reported (Figure 3). Interestingly, both the carbonyl oxygen and chlorine atoms of the 1-naphthoyl chloride molecule formed hydrogen bonds with the 3-OH group of the upper and lower TIPS- $\beta-\mathrm{CDs}$, respectively (the $\mathrm{O} \cdots \mathrm{O}$ and $\mathrm{Cl} \cdots \mathrm{O}$ distances are 2.68 and $3.14 \AA$, respectively).

The $\mathrm{CH} / \pi$ interaction between the $\mathrm{C}-\mathrm{H}$ group of cyclohexane and the naphthalene ring of $\mathbf{4 i}$ appears to contribute somewhat to the stabilization of the naphthalene moiety of $\mathbf{4 i}$ within the TIPS$\beta$-CD dimer cavity. ${ }^{11}$ These observations indicate that the combination of hydrogen bonds between $4 \mathbf{i}$ and TIPS- $\beta-C D$ and the $\mathrm{CH} / \pi$ interaction between $\mathbf{4 i}$ and cyclohexane inside the cavity plays a key role in forming a stable inclusion complex between them. To the best of our knowledge, this is the first example of a crystalline structure for an inclusion complex between a cyclodextrin derivative and an acyl chloride. ${ }^{11}$

\section{Conclusion}

In conclusion, we have demonstrated that the non-enzymatic kinetic resolution of primary amines via enantioselective $\mathrm{N}$ acylation with acyl chlorides can be realized by using the selective sequestration of one enantiomer within the supramolecular $\mathrm{CD}$ nanocapsule in nonpolar solvents. In particular, the kinetic resolution of racemic 1-(1naphthyl)ethylamine via enantioselective $N$-acylation with benzoyl chloride in the presence of a supramolecular TIPS- $\beta$-CD nanocapsule proceeded with high enantioselectivity and s-factor $(90 \% e e, s=20)$. Furthermore, we reported the first example of a crystal structure for an inclusion complex between an acyl chloride and a CD derivative. Further studies on the applications 
Tetrahedron

of 6-O-modified $\mathrm{CDs}$ as a supramolecular nanocapsule are now in progress at our laboratory. 
Table 1. Association constants between 6- $O$-silylated $\beta$-CD and $(R)$ - or $(S)-\mathbf{1 ,}, \mathbf{2}$, and $\mathbf{3}$ in nonpolar solvents at 10 or $25{ }^{\circ} \mathrm{C}$.

\begin{tabular}{|c|c|c|c|c|c|c|}
\hline \multirow{2}{*}{ entry } & \multirow{2}{*}{ CDs } & \multirow{2}{*}{ solvent } & \multirow{2}{*}{$\mathrm{T}\left({ }^{\circ} \mathrm{C}\right)$} & \multicolumn{2}{|c|}{ association constant } & \multirow{2}{*}{$\frac{\text { selectivity }}{K_{S} / K_{R}}$} \\
\hline & & & & $K_{R}$ & $K_{S}$ & \\
\hline & & & & \multicolumn{2}{|c|}{$(R)-$ or $(S)-\mathbf{1} / \mathrm{M}^{-2}$} & \\
\hline $1^{\mathrm{a}}$ & TIPS- $\beta-C D$ & cyclohexane- $d_{12}$ & 10 & $(1.5 \pm 0.52) \times 10^{6}$ & $(6.1 \pm 2.1) \times 10^{9}$ & $41 \pm 13$ \\
\hline $2^{\mathrm{a}}$ & TIPS- $\beta-C D$ & cyclohexane- $d_{12}$ & 25 & $(4.2 \pm 0.96) \times 10^{6}$ & $(1.3 \pm 0.20) \times 10^{8}$ & $31 \pm 6.1$ \\
\hline $3^{\mathrm{a}}$ & TIPS- $\beta-C D$ & benzene- $d_{6}$ & 25 & $(1.5 \pm 0.31) \times 10^{6}$ & $(1.8 \pm 0.41) \times 10^{7}$ & $12 \pm 2.6$ \\
\hline 4 & TBDMS- $\beta-C D$ & cyclohexane- $d_{12}$ & 25 & $(1.8 \pm 0.40) \times 10^{5}$ & $(1.2 \pm 0.33) \times 10^{6}$ & $6.1 \pm 1.6$ \\
\hline $5^{\mathrm{a}}$ & TIPS- $\beta-C D$ & cyclohexane- $d_{12}$ & 25 & $(1.2 \pm 0.12) \times 10^{7}$ & $(2.7 \pm 0.18) \times 10^{7}$ & $2.3 \pm 0.21$ \\
\hline 6 & TIPS- $\beta-C D$ & cyclohexane- $d_{12}$ & 25 & $(2.2 \pm 0.49) \times 10^{2}$ & $(2.3 \pm 0.40) \times 10^{2}$ & $1.0 \pm 0.22$ \\
\hline
\end{tabular}

Table 4. Enantioselective $N$-acylation of $\mathbf{1}$ with acyl chlorides $\mathbf{4 a - j}$ in the presence of TIPS- $\beta$-CD and association constants $(K)$ between TIPS- $\beta$-CD and $\mathbf{4 a - j}$ in cyclohexane $^{\mathrm{a}, \mathrm{b}}$

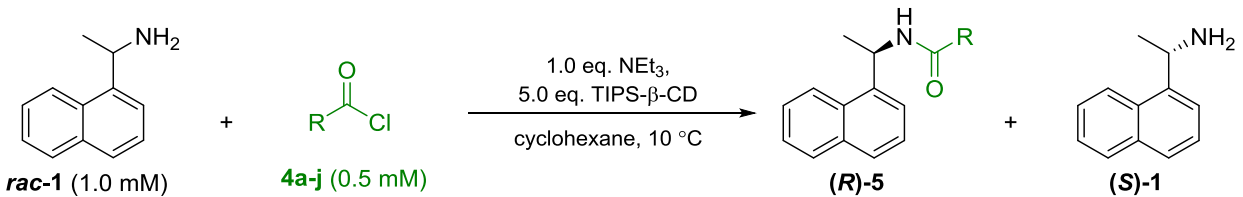

rac-1 $(1.0 \mathrm{mM})$

$4 a-j(0.5 \mathrm{mM})$

(R)-5

$(S)-1$

\begin{tabular}{|c|c|c|c|c|c|c|c|c|c|c|c|c|c|}
\hline \multirow[b]{2}{*}{ Entry } & \multirow[b]{2}{*}{ acyl chlorides } & \multicolumn{3}{|c|}{ product 5} & \multirow[b]{2}{*}{$s$} & \multirow[b]{2}{*}{$K^{b}\left(\mathrm{M}^{-2}\right)$} & \multirow[b]{2}{*}{ Entry } & \multirow[b]{2}{*}{ acyl chlorides } & \multicolumn{3}{|c|}{ product 5} & \multirow[b]{2}{*}{$s$} & \multirow[b]{2}{*}{$K^{b}\left(\mathrm{M}^{-2}\right)$} \\
\hline & & & conv. $^{\mathrm{c}}(\%)$ & $e e^{c}(\%)$ & & & & & & onv. ${ }^{c}(\%)$ & $e e^{c}(\%)$ & & \\
\hline $\begin{array}{l}1 \\
2^{d}\end{array}$ & & $\begin{array}{l}5 a \\
5 a\end{array}$ & $\begin{array}{l}44 \\
46\end{array}$ & $\begin{array}{l}77 \\
76\end{array}$ & $\begin{array}{l}14 \\
14\end{array}$ & $\sim 0$ & 8 & & $5 g$ & 41 & 75 & 12 & $(7.0 \pm 2.5) \times 10$ \\
\hline $3^{e}$ & $\widehat{4 b}$ & $5 b$ & 45 & 58 & 6 & $-f$ & & & & & & & \\
\hline 4 & 4c & $5 c$ & 42 & 64 & 7 & $-f$ & 9 & $4 \mathrm{~h}$ & $5 \mathrm{~h}$ & 50 & 70 & 12 & $(1.3 \pm 0.2) \times 10$ \\
\hline 5 & $\mathrm{Ad}^{\mathrm{Cl}}$ & $5 d$ & 46 & 65 & 8 & $\sim 0$ & 10 & & $5 \mathbf{i}$ & 15 & 65 & 5 & $(2.7 \pm 0.3) \times 10^{6}$ \\
\hline 6 & $4 e^{C l}$ & $5 e$ & 43 & 74 & 12 & $-f$ & & & & & & & \\
\hline 7 & $\mathrm{Cl}$ & $5 f$ & 45 & 75 & 13 & $\sim 0$ & 11 & $4 j$ & $5 j$ & n.d. & - & - & $-f^{\prime}$ \\
\hline
\end{tabular}

${ }^{a} \mathrm{~N}$-Acylation of $\mathbf{1}(1.0 \mathrm{mM})$ was carried out with acyl chlorides $\mathbf{4 a - j}$ in cyclohexane $(0.6 \mathrm{~mL})$ at $10{ }^{\circ} \mathrm{C}$ for $5 \mathrm{~h}$ in the presence of TIPS- $\beta$-CD (5.0 equiv.) and triethylamine (1.0 equiv.) ${ }^{b}$ Determined by NMR titration in cyclohexane- $d_{12}$ at $25^{\circ} \mathrm{C}$.

${ }^{\mathrm{c}}$ Conversion of $\mathbf{1}$ and enantiomeric excess of $(R)-\mathbf{5 a}$-i were determined by HPLC.

${ }^{\mathrm{d}} \mathrm{N}$-Acylation of $\mathbf{1}(0.1 \mathrm{mmol})$ was carried out with benzoyl chloride $\mathbf{4 a}$ in cyclohexane $(100 \mathrm{~mL})$ at $10{ }^{\circ} \mathrm{C}$ for $12 \mathrm{~h}$ in the presence of TIPS- $\beta$-CD $(5.0$ equiv., $1.1 \mathrm{~g})$ and triethylamine (1.0 equiv.).

e $0.6 \mathrm{mM}$ of acid chlorides were used.

${ }^{f}$ The shift of proton signals of TIPS- $\beta-C D$ was not observed. 


\section{Experimental Section}

\subsection{Determination of association constants by NMR spectroscopy.}

In the complexation of a heptakis(6- $O$-triisopropylsilyl)- $\beta$-cyclodextrin (TIPS- $\beta$-CD) host or a heptakis(6-O-tert-butyldimethylsilyl)- $\beta$-cyclodextrin (TBDMS- $\beta$-CD) host with $\mathbf{1}, \mathbf{3}$, and $\mathbf{4 g - i}$ in cyclohexane- $d_{12}$ at $25^{\circ} \mathrm{C}$, a solution of the host molecule $(600 \mu \mathrm{L}, 1.0$ $\mathrm{mM}$ ) was titrated in a NMR tube with increasing amounts of the guest stock solution. The titration curves (changes in the chemical shift of the host protons $(\Delta \delta)$ against the guest/host concentration ratio) were analyzed by a non-linear least-squares curve fitting method to generate association constants $(K)$ for the host-guest complexes. In the complexation of TIPS- $\beta$-CD (host) with $4 \mathbf{i}$ (guest) in cyclohexane- $d_{12}$ at $25{ }^{\circ} \mathrm{C}$, the exchange of complexed and uncomplexed hosts was slow on the NMR time scale. Thus, the association constant $(K)$ was determined by the integration of the NMR signals for complexed and uncomplexed hosts.

For a 2:1 host-guest complex, the following expression can be written

$\begin{aligned} & 2 \text { host }+ \text { guest }\text { Thest) })_{2} \text { (guest) } \\ & \text { The association constant is given by eq } 1\end{aligned}$

$K=\left[(\text { host })_{2} \cdot\right.$ (guest) $] /[\text { host }]^{2}$ [guest $]$

where [host], [guest], and [(host) $2^{\bullet}$ (guest)] are equilibrium concentrations.

On the other hand, for a 1:1 host-guest complex, the following expression can be written: host + guest $\rightleftarrows$ host•guest

The association constant is given by eq 2 $K=[$ host $\bullet$ guest $] /[$ host $][$ guest $] \quad$ (2)

where [host], [guest], and [host•guest] are equilibrium concentrations.

\subsection{Experimental procedure for Job plots.}

In the complexation of TIPS- $\beta-\mathrm{CD}$ or TBDMS- $\beta-\mathrm{CD}$ (host) with each guest in cyclohexane- $d_{12}$, Job plots were made by monitoring the changes in the chemical shift of the host protons $(\Delta \delta)$ in a series of solutions with varying host/guest ratios, but with the total concentration of the host and guest kept constant $(2.0$ or $0.8 \mathrm{mM})$. The relative concentration of the host-guest complex estimated from the $\Delta \delta \cdot[$ host] value was then plotted against ([host $] /\{[$ host $]+[$ guest $]\})$.

\subsection{Enantioselective $N$-acylation of primary amines.}

The $N$-acylation of racemic $\mathbf{1}, \mathbf{2}$, and $\mathbf{3}$ was carried out with acyl chlorides as acylation reagents and triethylamine as the base in cyclohexane in the presence and absence of TIPS- $\beta$-CD. After a mixture of racemic 1, 2, and $3\left(6.0 \times 10^{-4} \mathrm{mmol}\right)$ and $6-O$-silylated $\beta$ $\mathrm{CD}$ was stirred for $1 \mathrm{~h}$ in cyclohexane $(600 \mu \mathrm{L})$ to reach the complexation equilibrium between 1, 2, and 3 and $6-O$-silylated $\beta-\mathrm{CD}$, triethyamine $\left(6.0 \times 10^{-4} \mathrm{mmol}\right)$, the acyl chlorides $\mathbf{4 a - j}$ were added at $10{ }^{\circ} \mathrm{C}$. The mixture was then stirred at $10{ }^{\circ} \mathrm{C}$ for $6 \mathrm{~h}$. The resulting products were analyzed by HPLC using the chiral phase column Diacel Chiralcel OD-H $(250 \mathrm{~mm} \times 4.6 \mathrm{~mm}$ i.d. $)$ using hexane $/ 2$-propanol $=80 / 20$ or $95 / 5$ as an eluent at a flow rate of 0.5 or $1.5 \mathrm{ml} \mathrm{min}^{-1}$ using UV detection $(254 \mathrm{~nm})$. The HPLC charts of the products obtained after $N$-acylation of $\mathbf{1}, \mathbf{2}$, and $\mathbf{3}\left(6.0 \times 10^{-4} \mathrm{mmol}\right)$ with acyl chlorides $4 \mathbf{4 a - j}\left(3.3 \times 10^{-4} \mathrm{mmol}\right)$ in cyclohexane $(600 \mu \mathrm{L})$ including triethylamine $\left(6.0 \times 10^{-4} \mathrm{mmol}\right)$ in the absence and presence of TIPS- $\beta$-CD $\left(3.0 \times 10^{-3} \mathrm{mmol}\right)$ are shown in Figures S18-26, respectively.

\subsection{Analytics.}

${ }^{1} \mathrm{H}$ and ${ }^{13} \mathrm{C}$ NMR spectra were recorded on a JEOL NMR system (400 MHz) in DMSO$d_{6}$ and the chemical shifts in ppm refer to DMSO $\left(\delta_{\mathrm{H}} 2.50, \delta_{\mathrm{C}} 39.52\right)$ as an internal standard. The following abbreviations were used for chemical shift mutiplicities: $\mathrm{s}=$ singlet, $\mathrm{d}=$ doublet $\mathrm{t}=$ triplet, $\mathrm{q}=$ quartet, $\mathrm{m}=$ multiplet. NMR signal assignments were based on additional 2D-NMR spectroscopy (e.g., COSY, NOESY, HSOC, and HMBC) Infrared (IR) spectra were obtained with a Spectrum 100FT-IR spectrometer (Perkin Elmer). Melting points were determined on a Stanford Research Systems MPA100 OptiMelt Automated Melting Point System and are uncorrected. High-resolution mass spectra were obtained on a JEOL JMS-DX303HF mass spectrometer.

\subsection{Crystal structure determination.}

X-ray diffraction data were collected on a Rigaku R-AXIS RAPID diffractometer with a $2 \mathrm{D}$ area detector using graphite-monochromatized $\mathrm{Cu} \mathrm{K \alpha}$ radiation $(\lambda=1.54178 \AA)$. Direct methods (SIR-2002) were then used to solve for the structure. ${ }^{12}$ All calculations were performed with the observed reflections $[I>2 \sigma(I)]$ using the CrystalStructure crystallographic software package ${ }^{14}$ except for refinements, which were performed using SHELXL-97. ${ }^{15}$ Non-hydrogen atoms were refined with anisotropic displacement parameters, except for the carbon atoms of the triisopropylsilyl groups and cyclohexane molecules placed around the rim of TIPS- $\beta-C D$, which were refined isotropically owing to their high thermal parameters. About half of the triisopropylsilyl groups were clearly disordered over two or more positions, which were refined as disordered groups. Hydrogen atoms were placed in their idealized positions and refined as rigid atoms with the relative isotropic displacement parameters. Although the gaps between the TIPS- $\beta$ CD supramolecular dimers in the structure must be occupied by cyclohexane molecules, they were all of highly disordered with no possibility of refining them reasonably. To improve their refinement, they were removed using the SQUEEZE routine implemented in the PLATON software package. ${ }^{16}$ Crystallographic data for the structure reported in this paper have been deposited with the Cambridge Crystallographic Data Center as supplementary publication no.CCDC-953149 (TIPS- $\beta-C D-4 i$ inclusion complex). Copies of the data can be obtained free of charge on application to CCDC,12 Union
Road, Cambridge CB2 1EZ, UK (fax: p44 $1223 \quad 336$ 033; e-mail: deposit@ccdc.cam.ac.uk).

\subsection{Analytical data of the products}

The spectral data for known compounds, $N$-benzoyl-1 (= 5a), 5b, 5c, $N$-benzoyl-2, and $N$-benzoyl-3, were found to be identical to those described in the literature [ $N$-benzoyl-1, $\mathbf{2}$, and $\left.3,{ }^{17} \mathbf{5 b},{ }^{18} 5 \mathbf{c} \cdot{ }^{19}\right] .5 \mathrm{~d}-\mathbf{i}$ (racemic mixtures) described below were synthesized for the analysis by $N$-acylation of rac-1 with the corresponding acyl chlorides in the absence of TIPS- $\beta-C D$.

( \pm )- $\boldsymbol{N}$-(1-(naphthalen-1-yl)ethyl)pivalamide $5 \mathrm{~d}$ : white powder, mp. $143-144{ }^{\circ} \mathrm{C}$ (from hexane/chloroform). ${ }^{1} \mathrm{H}$ NMR $\left(\mathrm{CDCl}_{3}\right) \delta 1.23(\mathrm{~s}, 9 \mathrm{H}), 1.58(\mathrm{~d}, J=6.3 \mathrm{~Hz}, 3 \mathrm{H}), 3.41(\mathrm{br}$, $1 \mathrm{H}), 5.00(\mathrm{q}, J=6.3 \mathrm{~Hz}, 1 \mathrm{H}), 7.46-7.56(\mathrm{~m}, 3 \mathrm{H}), 7.63(\mathrm{~d}, J=7.3 \mathrm{~Hz}, 1 \mathrm{H}), 7.76(\mathrm{~d}, J=$ $8.2 \mathrm{~Hz}, 1 \mathrm{H}), 7.88(\mathrm{~d}, J=8.2 \mathrm{~Hz}, 1 \mathrm{H}), 8.13(\mathrm{~d}, J=8.6 \mathrm{~Hz}, 1 \mathrm{H}) .{ }^{13} \mathrm{C}$ NMR $\left(\mathrm{CDCl}_{3}\right) \delta$ 24.8, 27.6, 39.0, 46.8, 121.8, 123.3, 126.0, 126.1, 126.6, 127.9, 129.5, 131.1, 134.4, 168.6. IR : $1613.6(\mathrm{C}=\mathrm{O})$. HRMS (EI) $\mathrm{m} / z$ calcd. for $\mathrm{C}_{17} \mathrm{H}_{21} \mathrm{NO}: 255.1623$, found 255.1625 .

( \pm )- $N$-(1-(naphthalen-1-yl)ethyl)octanamide $5 \mathrm{e}$ : white powder, $\mathrm{mp} .94-95{ }^{\circ} \mathrm{C}$ (from hexane/chloroform). ${ }^{1} \mathrm{H}$ NMR $\left(\mathrm{CDCl}_{3}\right) \delta 0.83-0.88(\mathrm{t}, J=6.8, \mathrm{~Hz}, 3 \mathrm{H}), 1.19-1.31(\mathrm{~m}, 8$ H), $1.59-1.63(\mathrm{~m}, 2 \mathrm{H}), 1.67(\mathrm{~d}, J=6.8 \mathrm{~Hz}, 3 \mathrm{H}), 2.09-2.18(\mathrm{~m}, 2 \mathrm{H}), 5.69$ (br, $1 \mathrm{H})$, $5.94(\mathrm{dq}, J=6.8,7.2 \mathrm{~Hz}, 1 \mathrm{H}), 7.43-7.56(\mathrm{~m}, 4 \mathrm{H}), 7.80(\mathrm{~d}, J=8.2 \mathrm{~Hz}, 1 \mathrm{H}), 7.87(\mathrm{~d}, J=$ $7.7 \mathrm{~Hz}, 1 \mathrm{H}), 8.09(\mathrm{~d}, J=8.2 \mathrm{~Hz}, 1 \mathrm{H}) .{ }^{13} \mathrm{C} \mathrm{NMR}\left(\mathrm{CDCl}_{3}\right) \delta 14.2,20.7,22.7,25.9,29.1$, $29.3,31.8,37.0,44.5,122.7,123.7,125.3,126.0,126.7,128.5,128.9,131.3,134.0$ 138.4, 172.1. IR : 1625.7 (C=O). HRMS (EI) $\mathrm{m} / z$ calcd. for $\mathrm{C}_{20} \mathrm{H}_{27} \mathrm{NO}: 297.2093$, found 297.2097.

( \pm )- $\boldsymbol{N}$-(1-(naphthalen-1-yl)ethyl)cyclohexanecarboxamide 5f: white powder, mp. $161{ }^{\circ} \mathrm{C}$ (from hexane/chloroform). ${ }^{1} \mathrm{H}$ NMR $\left(\mathrm{CDCl}_{3}\right) \delta 1.18-1.21(\mathrm{~m}, 3 \mathrm{H}), 1.39-1.46(\mathrm{~m}$ $2 \mathrm{H}), 1.63-1.67(\mathrm{~m}, 4 \mathrm{H}), 1.70-1.81(\mathrm{~m}, 3 \mathrm{H}), 1.85(\mathrm{~d}, J=11.9 \mathrm{~Hz}, 1 \mathrm{H}), 2.03(\mathrm{dd}, J=$ $8.2,8.2 \mathrm{~Hz}, 1 \mathrm{H}) 5.63(\mathrm{~m}, 1 \mathrm{H}), 5.90(\mathrm{q}, J=8.6 \mathrm{~Hz}, 1 \mathrm{H}), 7.41-7.55(\mathrm{~m}, 4 \mathrm{H}), 7.78-7.81$ $(\mathrm{m}, 1 \mathrm{H}), 7.84-7.87(\mathrm{~m}, 1 \mathrm{H}), 8.04-8.07(\mathrm{~m}, 1 \mathrm{H}) .{ }^{13} \mathrm{C} \mathrm{NMR}\left(\mathrm{CDCl}_{3}\right) \delta 20.7,25.8,29.7$, 29.9, 44.4, 45.8, 122.6, 123.8, 125.3, 126.0, 126.6, 128.5, 128.9, 131.4, 134.1, 138.5, 175.0. IR : $1625.9(\mathrm{C}=\mathrm{O}) \mathrm{HRMS}$ (EI) $\mathrm{m} / z$ calcd. for $\mathrm{C}_{19} \mathrm{H} 23 \mathrm{NO}: 281.1780$, found 281.1782 .

( \pm )-(3r,5r,7r)- $N$-(1-(naphthalen-1-yl)ethyl)adamantane-1-carboxamide $\quad 5 g$ : white powder, mp. $187-188{ }^{\circ} \mathrm{C}$ (from hexane/chloroform). ${ }^{1} \mathrm{H}$ NMR $\left(\mathrm{CDCl}_{3}\right) \delta 1.64(\mathrm{~d}, J=6.9$ $\mathrm{Hz}, 3 \mathrm{H}), 1.63-1.73(\mathrm{~m}, 6 \mathrm{H}), 1.82-1.83(\mathrm{~m}, 6 \mathrm{H}), 1.99-2.11(\mathrm{~m}, 3 \mathrm{H}), 5.78(\mathrm{~d}, J=7.3 \mathrm{~Hz}$, $1 \mathrm{H}), 5.91(\mathrm{dq}, J=6.9,7.3 \mathrm{~Hz}, 1 \mathrm{H}), 7.43-7.55(\mathrm{~m}, 4 \mathrm{H}), 7.79(\mathrm{~d}, J=8.2 \mathrm{~Hz}, 1 \mathrm{H}), 7.87$ $(\mathrm{d}, J=7.8 \mathrm{~Hz}, 1 \mathrm{H}), 8.04(\mathrm{~d}, J=8.2 \mathrm{~Hz}, 1 \mathrm{H}) .{ }^{13} \mathrm{C}$ NMR $\left(\mathrm{CDCl}_{3}\right) \delta 20.8,28.2,36.6,39.3$, $40.7,44.4,122.6,123.8,125.3,126.0,126.6,128.5,128.8,131.4,134.1,138.7,176.9$. IR : $1648.2(\mathrm{C}=\mathrm{O})$. HRMS (EI) $\mathrm{m} / \mathrm{z}$ calcd. for $\mathrm{C}_{23} \mathrm{H}_{27} \mathrm{NO}: 333.2093$, found 332.2095

( \pm )-2,4-dichloro- $\boldsymbol{N}$-(1-(naphthalen-1-yl)ethyl)benzamide $5 \mathbf{h}$ : white powder, $\mathrm{mp} .153$ $154{ }^{\circ} \mathrm{C}$ (from hexane/chloroform). ${ }^{1} \mathrm{H} \mathrm{NMR}\left(\mathrm{CDCl}_{3}\right) \delta 1.69(\mathrm{~d}, J=6.8 \mathrm{~Hz}, 3 \mathrm{H}), 5.95$ $6.04(\mathrm{~m}, 1 \mathrm{H}), 6.41(\mathrm{br}, 1 \mathrm{H}), 7.11-7.19(\mathrm{~m}, 1 \mathrm{H}), 7.33-7.38(\mathrm{~m}, 1 \mathrm{H}), 7.40-7.49(\mathrm{~m}, 5$ $\mathrm{H}), 7.71(\mathrm{~d}, J=8.2 \mathrm{~Hz}, 1 \mathrm{H}), 7.78(\mathrm{~d}, J=8.2 \mathrm{~Hz}, 1 \mathrm{H}), 8.09(\mathrm{~d}, J=8.2 \mathrm{~Hz}, 1 \mathrm{H}) .{ }^{13} \mathrm{C}$ NMR $\left(\mathrm{CDCl}_{3}\right) \delta 20.7,45.8,122.9,123.6,125.3,126.1,126.7,127.5,128.7,129.0,130.1$, $131.1,131.2,131.7,133.6,134.1,136.8,137.7,164.6$. IR : 1678.8 (C=O). HRMS (EI) $\mathrm{m} / \mathrm{z}$ calcd. for $\mathrm{C}_{19} \mathrm{H}_{15} \mathrm{Cl}_{2} \mathrm{NO}: 343.0531$, found 343.0534 .

( \pm - $N$-(1-(naphthalen-1-yl)ethyl)-1-naphthamide $\mathbf{5 i}$ : white powder, mp. $177-178{ }^{\circ} \mathrm{C}$ (from hexane/chloroform). ${ }^{1} \mathrm{H}$ NMR $\left(\mathrm{CDCl}_{3}\right) \delta 1.86(\mathrm{~d}, J=6.4 \mathrm{~Hz}, 3 \mathrm{H}), 6.23(\mathrm{br}, 1 \mathrm{H})$, $6.26(\mathrm{q}, J=6.4 \mathrm{~Hz}, 1 \mathrm{H}), 7.38(\mathrm{dd}, J=7.3,7.7 \mathrm{~Hz}, 1 \mathrm{H}), 7.45-7.56(\mathrm{~m}, 5 \mathrm{H}), 7.40-7.49$ $(\mathrm{m}, 5 \mathrm{H}), 7.57-7.65(\mathrm{~m}, 2 \mathrm{H}), 7.82-7.91(\mathrm{~m}, 4 \mathrm{H}), 8.31-8.36(\mathrm{~m}, 2 \mathrm{H}) .{ }^{13} \mathrm{C}$ NMR $\left(\mathrm{CDCl}_{3}\right) \delta 20.8,45.3,122.8,123.7,124.8,124.9,125.3,125.5,126.2,126.6,126.9$, $127.3,128.4,128.7,129.0,130.3,130.7,131.4,133.8,134.2,134.6,138.1,168.6$. IR : $1615.2(\mathrm{C}=\mathrm{O})$. HRMS (EI) $\mathrm{m} / z$ calcd. for $\mathrm{C}_{23} \mathrm{H}_{19} \mathrm{NO}: 325.1467$, found 325.1464

\section{Acknowledgements}

This work was supported by the Funding Program for Next Generation World-Leading Researchers (GR067).

\section{Supplementary Material}

Supplementary data associated with this article can be found, in the online version, at

\section{References and notes}

1. For selected reviews, see: (a) North, M. J. Chem. Soc. Perkin Trans. 1 1998, 2959-2972; (b) Gomez, S. Peters, J. A. Maschmeyer, T. Adv. Synth. Catal. 2002, 344, 1037-1057; (c) Breuer, M.; Ditrich, K.; Habicher, T.; Hauer, B.; Keßeler, M.; Sturmer, R.; Zelinski, T. Angew. Chem., Int. Ed. 2004, 43, 788824; (d) Dalko, P. I., Ed. Enantioselective Organocatalysis; Wiley-VCH: Weinheim, 2007; (e) Nugent, T. C. M. El-Shazly, Adv. Synth. Catal. 2010, 352, 753-819; (f) Nugent, T. C., Ed 
Chiral Amine Synthesis: Methods, Development and Applications; Wiley-VCH Verlag: Weinheim, 2010.

2. Arai, S.; Bellemin-Laponnaz, S.; Fu, G. C. Angew. Chem.,Int. Ed., 2001, 40, 234-236.

3. For recent reviews, see: (a) Pellissier, H. Adv. Synth. Catal. 2011, 353, 1613; (b) Krasnov, P. V.; Gruzdev, A. D.; Levit, L. G. Eur. J. Org. Chem. 2012, 1471-1493. For examples of non-enzymatic KR of primary amines, see (c) Arnold, K.; Davies, B.; Hérault, D.; Whiting, A. Angew. Chem., Int. Ed. 2008, 47, 2673-2676; (d) Klauber, E. G.; De, C. K.; Shah, T. K.; Seidel, D. J. Am. Chem. Soc., 2010, 132, 13624-13626; (e) Klauber, E. G.; Mittal, N.; Shah T. K.; Seidel, D. Mittal, Org. Lett. 2011, 13, 2464-2467; (f) Mittal, N.; Sun, D. X.; Seidel, D. Org. Lett. 2012, 14, 3084-3087; (g) Kolleth, A.; Christoph, S.; Arseniyadis, S.; Cossy, J. Chem. Commun. 2012, 48, 10511-10513; (h) Min, C.; Mittal, N.; De, C. K.; Seidel, D. Chem. Commun. 2012, 48, 10853-10855; (i) Krasnov, V. P.; Gruzdev, D. A.; Levit, G. L. Eur. J. Org. Chem. 2012, 1471-1493; (j) Yang, W.; Long, Y.; Zhang, S.; Zeng, Y.; Cai, Q. Org. Lett. 2013, 15, 3598-3601.

4. (a) Fiedler, D.; Leung, D. H.; Bergman, R. G.; Raymond, K. N. Acc. Chem. Res. 2005, 38, 349-358; (b) Iwasawa, T.; Hooley, R. J.; Rebek, J. Jr. Science 2007, 317, 493-496; (c) Pluth, M. D.; Bergman, R. G.; Raymond, K. N. Acc. Chem. Res. 2009, 42, 1650-1659; (d) Ballester, P. Chem. Soc. Rev. 2010, 39, 3810-3830; (e) Jian, W.; Ajami, D.; Rebek, J., Jr. J. Am. Chem. Soc. 2012, 134, 8070-8073; (f) Koblenz, T. S.; Wassenaar, J.; Reek, J. N. H. Chem. Soc. Rev. 2008, 37, 247-262; (g) Yoshizawa, M.; Klosterman, J. K.; Fujita, M. Angew. Chem., Int. Ed. 2009, 48, 3418-3438; (h) Cavarzan, A.; Scarso, A.; Sgarbossa, P.; Strukul, G.; Reek, J. N. H. J. Am. Chem. Soc. 2011, 133, 2848-2851.

5. Liu, S.; Gan, H.; Hermann, A. T.; Rick, S. W.; Gibb. B. C. Nat. Chem. 2010, 2, 847-852.

6. Kida, T.; Iwamoto, T.; Asahara, H.; Hinoue, T.; Akashi, M. J. Am. Chem. Soc. 2013, 135, 3371-3374.

7. The kinetics of the reactions of benzoyl chloride with amines and the electrophilicities of the benzoyl chloride were reported by Mayr et al., see; Nigst, T. A.; Mayr, H. Eur. J. Org. Chem, 2013, 2155-2163.

8. The $s$ factor is defined as $s=$ (rate of the faster-reacting enantiomer)/(rate of the slower-reacting enantiomer). Values of s were calculated using Kagan's method. See: Kagan, H. B.; Fiaud, J. C. Top. Stereochem.1988, 18, 249-330.

9. Acylation of 2- or 3-OH groups of 6-O-silylated CDs with acyl chlorides needs the heating condition and long reaction time to be performed, example see; Zhang, P.; Ling, C.-C.; Coleman, A. W.; Parrot-Lopez, H.; Galons, H. Tetrahedron Lett. 1991, 32, 27692770.

10. Kida, T.; Iwamoto. T.; Fujino, Y.; Tohnai, N.; Miyata, M.; Akashi, M. Org. Lett. 2011, 13, 4570-4573.

11. In the crystal structure of the TIPS- $\beta$-CD-4i inclusion complex, the $\mathrm{CH} / \pi$ interactions between three $\mathrm{C}-\mathrm{H}$ groups of cyclohexanes and the naphthalene ring of $\mathbf{4 i}$ were observed, and the distances between these cyclohexane carbons and the naphthalen ring of $4 \mathbf{i}$ are 3.50, 3.56, and $3.67 \AA$, respectively. For references on $\mathrm{CH} / \pi$ interactions, see; (a) Takahashi, O.; Kohno, Y.; Iwasaki, S.; Saito, K.; Iwaoka, M.; Tomoda, S.; Umezawa, Y.; Tsuboyama, S.; Nishio, M. Bull. Chem. Soc. Jpn. 2001, 74, 2421-2430; (b) Desiraju, G. R. Acc. Chem. Res. 2002, 35, 565-573; (c) Tsuzuki, S Annu. Rep. Prog. Chem., Sect. C: Phys. Chem. 2012, 108, 69-95.

12. One example of the inclusion complex between $C D$ and acyl chloride (valeryl chloride) has been reported, but there is no spectroscopic evidence for the formation of this complex, see; Glazyrin, A. E.; Syrtsev, A. N.; Kurochkina, G. I.; Kononov, L. O.; Grachev, M. K.; Nifantév, E. E. Russ. Chem. Bull. 2003, 52, 237-246.

13. Burla, M. C.; Camalli, M.; Carrozzini, B.; Cascarano, G. L.; Giacovazzo, C.; Polidori, G.; Spagna, R. J Appl Crystallogr. 2003, 36, 1103 .

14. Crystal Structure 4.0: Crystal Structure Analysis Package; Rigaku Corp., Tokyo, Japan, 2000-2010.

15. Sheldrick, G. M. Acta Crystallogr., Sect. A 2008, 64, 112-122.

16. Spek, A. L. J. Appl. Crystallogr. 2003, 36, 7-13.

17. De, C. K.; Klauber, E. G.; Seidel, D. J. Am. Chem. Soc. 2009, 131, 17060-17061

18. Li, G.; Antilla, J. C. Org. Lett. 2009, 11, 1075-1078.

19. Streuff, J.; Muniz, K. J. Organomet. Chem. 2005, 690, 5973-5978. 